Bull. Chem. Soc. Ethiop. 2016, 30(3), 391-401.

Printed in Ethiopia

DOI: http://dx.doi.org/10.4314/bcse.v30i3.7

ISSN 1011-3924

(C) 2016 Chemical Society of Ethiopia

\title{
COMBINED ALUMINIUM SULFATE/HYDROXIDE PROCESS FOR FLUORIDE REMOVAL FROM DRINKING WATER
}

\author{
Feleke Zewge* \\ Addis Ababa University, College of Natural and Computational Sciences, Department of \\ Chemistry, P.O. Box 1176, Addis Ababa, Ethiopia
}

(Received April 16, 2016; revised December 12, 2016)

\begin{abstract}
In this study, aluminium hydro(oxide), AO was prepared from locally available aluminium sulfate, and used for fluoride removal from water by combining with Nalgonda Technique. The fluoride removal performance of the combined process was investigated as a function of contact time, proportion of alum-lime/AO dose, initial fluoride concentration and solution $\mathrm{pH}$ in series of batch experiments. The rate of fluoride removal was investigated using conventional kinetic models. The fluoride removal efficiency of the combined process was also tested for real water sample from selected community water supply system in the Rift Valley Region of Ethiopia. The removal of fluoride was rapid in the first $15 \mathrm{~min}$. The combined process efficiency was about $93 \%$ with an optimum combined alum/ $\mathrm{AO}$ dose $(80 \mathrm{mg}$ alum $/ \mathrm{mg} \mathrm{F}, 5 \mathrm{mg} \mathrm{AO} / \mathrm{mg} \mathrm{F}$ and lime $=35 \%$ of alum) using initial fluoride concentration of $15 \mathrm{mg} / \mathrm{L}$. The optimum solution $\mathrm{pH}$ for fluoride removal was in the range of 5-9, which is suitable for practical application in the Ethiopia Rift Valley Region. Kinetic studies showed that the rate of fluoride removal by alum/AO can be well described by a pseudo-second-order rate equation with an average rate constant of $0.096 \mathrm{~g} / \mathrm{minmg}$. The optimum dose required to attain $85-93 \%$ fluoride removal efficiency from real water sample was $90 \mathrm{mg}$ alum/mg F, $5 \mathrm{mg} \mathrm{AO} / \mathrm{mg} \mathrm{F}$, and $15 \%$ lime. Hence, the combined defluoridation process has higher fluoride removal efficiency than the Nalgonda Technique with an additional advantage of minimizing chemical dose. The reported removal efficiency of Nalgonda Technique is $70 \%$ at alum dose of 150 $170 \mathrm{mg}$ alum $/ \mathrm{mg}$ F. Besides, sludge production is also minimized. Therefore, this process is highly efficient and could be applied in areas where the fluoride concentration is higher than $10 \mathrm{mg} / \mathrm{L}$, both at household and community level.
\end{abstract}

KEY WORDS: Nalgonda Technique, Aluminium sulfate, Aluminium hydroxide, Fluoride, Drinking water

\section{INTRODUCTION}

Fluoride is a common constituent in natural waters or wastewaters. It may originate from either natural geological sources or industries that use fluoride-containing compounds as raw materials. The dissolution of fluoride in groundwater is dependent on chemical and physical processes that take place in the sub-surface environment. Among several fluoride bearing minerals, fluorite $\left(\mathrm{CaF}_{2}\right)$ is the predominant mineral that controls the dissolved fluoride concentration in the groundwater [1-3]. Thus, fluoride-rich ground waters are often associated with rocks with low calcium content or high-pH conditions where sodium bicarbonate dominates the groundwater composition [4].

Exposure to excess fluoride mainly through drinking water and food can have harmful effects on human health and could result in fluorosis. According to the World Health Organization (WHO), the maximum acceptable concentration of fluoride ions in drinking water is $1.5 \mathrm{mg} / \mathrm{L}$ [5]. Fluorosis (dental and skeletal) has been reported in several parts of the world including Ethiopia, where fluoride concentrations in drinking water exceed the WHO guideline value of $1.5 \mathrm{mg} / \mathrm{L}$ [5-11]. Groundwater sources used for drinking in Ethiopia contain fluoride up to $26 \mathrm{mg} / \mathrm{L}$ [12]. Yet, groundwater provides drinking water for large part of the population and is the sole source of drinking water for many rural communities and urban centers in the Rift Valley. More than 11 million people in the Ethiopian Rift Valley rely on drinking water contaminated with fluoride [13]. Over $40 \%$ of deep and shallow wells are contaminated and over $80 \%$ of children

${ }^{*}$ Corresponding author. E-mail: fbeshah@yahoo.com 
suffer from different degrees of dental fluorosis and skeletal fluorosis is increasing, mainly among older people [11]. It is expected that exposure to fluoride will increase as the water supply coverage from groundwater sources increases.

To mitigate the hazard of drinking high fluoride water, different natural or synthesized materials have been applied for water defluoridation, including calcite [14], montmorillonite [15], ando soil [16], zeolite [17], bentonite [18], and mesoporous magnesium oxide [19]. Moreover, adsorption of fluoride by different adsorbents such as fired clay chips [20], waste residue from alum manufacturing process [21], untreated hydrated alumina (UHA) which is sun dried and thermally treated hydrated alumina (THA) obtained from hydrolysis of locally manufactured aluminum sulfate [22], aluminium oxide-manganese oxide composite material [23], nanoscale aluminium oxide hydroxide (AlOOH) [24] and natural zeolite [25], were among several attempts which have been made in Ethiopia for defluoridation of drinking water.

Precipitation methods have been found generally effective in the defluoridation of drinking water; however, they are unsuccessful in bringing fluoride down to desired concentration levels [26]. The Nalgonda Technique developed by National Environmental Engineering Research Institute (NEERI) is one of the most widely used defluoridation method in India, particularly at the community level [27-29]. It has also been used for defluoridation of water in developing countries (e.g. India, Kenya, Senegal and Tanzania) [26]. The possibility of using aluminium sulfate and lime combination to precipitate fluoride has also been tested in Ethiopia [30]. The process is based on the addition of specified quantities of alum, lime, and calcium hypochlorite to raw water, followed by mixing, flocculation, sedimentation, and filtration. The insoluble aluminium hydroxide flocs formed during this process is responsible for the co-precipitation of the fluoride ions. The commonly used "fill and draw type" defluoridation unit for small community (around 200 people) requires $2-3$ h to complete the reaction and settling, with a number of batch operations in a day depending on the community water demand [26]. The disadvantages of this technique include high residual aluminium concentration $(2-7 \mathrm{mg} / \mathrm{L})$ in the treated water, high alum dose and the requirements for sludge disposal, low treatment efficiency and requirement of daily routine operation with good process control [26, 31, 32]. The Ministry of Water, Irrigation and Energy of Ethiopia is implementing the Nalgonda Technique in several villages, but the method is not suitable for treating water with high TDS and raw water fluoride concentration exceeding $10 \mathrm{mg} / \mathrm{L}$. The required chemical dose is about $170 \mathrm{mg}$ to remove 1 $\mathrm{mg}$ of fluoride with an additional lime dose $50 \%$ of alum which result in large amount of sludge. The treatment efficiency is limited to about $70 \%$ removal

In our previous study we have reported the performance of fluoride adsorption thermally treated and untreated aluminium hydroxide [26]. The minimum fluoride adsorption capacity of untreated and thermally treated aluminium hydroxide was found to be $7.9 \mathrm{mg} / \mathrm{g}$ and $23.7 \mathrm{mg} / \mathrm{g}$, respectively, based on the Fruendlich model [26]. Furthermore, we investigated the properties and fluoride-adsorption capacity of aluminium hydroxide-based (AO) adsorbent [4]. Depending on the conditions of precipitation and thermal treatment, the resultant material exhibit substantial differences not only in magnitudes of the specific surface area and pore size distribution but also in the surface properties. Surface acidity and surface site concentration were estimated by acid-base titration [33]. The results from these titrations indicated that the AO acidity was greater than its surface site concentration, and thus the acidity increases the fluoride adsorption capacity. This is because the concentration of both protonated surface sites and acid sites, which served as fluoride binding sites, increased significantly with decreasing $\mathrm{pH}$. Our previous study using mini-column experiments with $\mathrm{AO}(10 \mathrm{eBV} /$ day, $20 \mathrm{mg} / \mathrm{L}$ fluoride, $\mathrm{pH} 8 \pm$ $0.2,10 \mathrm{mM} \mathrm{NaHCO} 3,3,000 \mathrm{ppm} \mathrm{CO}$ ), showed that the adsorption capacity of AO was found to be $9.0 \mathrm{mg} \mathrm{F} / \mathrm{g}$ [4]. The AO was pilot tested in a rural community in the Ethiopian Rift Valley where groundwater is heavily enriched with fluoride.

However, the experiences from the AO community pilot plant indicate that the operational cost of AO should be reduced to a reasonable amount to make the technology sustainable in 
rural communities. Therefore, the combined alum/AO process is considered to be cost effective, affordable by communities at household/community defluoridation scale, and environmentally friendly.

The present work aims to improve the performance of Nalgonda Technology (NT) in terms of fluoride removal efficiency, raw material/chemical consumption and reduction of sludge by combining NT with high capacity AO material.

\section{EXPERIMENTAL}

\section{Defluoridation material preparation}

Aluminium sulfate (alum) was used as starting material for the production of AO. AO was prepared by mixing $100 \mathrm{~g}$ of $\mathrm{Al}_{2}\left(\mathrm{SO}_{4}\right)_{3} \cdot 14 \mathrm{H}_{2} \mathrm{O}$ in $500 \mathrm{~mL}$ of distilled water while stirring with magnetic stirrer until complete dissolution. The resulting lower $\mathrm{pH}$ (2.7) was adjusted to about $\mathrm{pH}$ of 7.00 using $2.0 \mathrm{M} \mathrm{NaOH}$ [4]. The precipitate (AO) was allowed to dry by exposure to sun light, and then washed with distilled water to remove $\mathrm{Na}_{2} \mathrm{SO}_{4}$ until $\mathrm{EC}$ of the material reduced to less than $1000 \mu \mathrm{S} / \mathrm{cm}$. The material was again sun dried and crashed to powder.

\section{Characterization of $A O$}

AO sample $(0.1 \mathrm{~g})$ was digested in a microwave digester in a $3: 1$ mixture $(4 \mathrm{~mL})$ of $30 \% \mathrm{HCl}$ and $65 \% \mathrm{HNO}_{3}$ for $80 \mathrm{~min}$. The resulting digest then diluted to $100 \mathrm{~mL}$ using deionized water (EPA, method 3051A, 2007). The elemental composition of AO was determined by ICP-MS (Agilent 7500CX, USA) and sulfate was determined by ion chromatography (Metrohm 761, Switzerland). The absolute density of the sample was determined by Pycnometer (MetroMetiricsAccuPyc 1330, USA). The weight loss of the samples was measured with a thermogravimetric analyzer (Mettler Toledo AG-TGA/SDTA851e, Switzerland) using ceramic crucible at a heating rate of $10^{\circ} / \mathrm{min}$ from room temperature to $1000{ }^{\circ} \mathrm{C}$. The X-ray diffraction (XRD) patterns of the adsorbents were recorded by an X-ray diffractometer (X'pert PRO, PANalytica, The Netherlands) using $\mathrm{Cu} \mathrm{K} \alpha$ radiation $(\lambda=0.1542 \mathrm{~nm})$ with a $0.05^{\circ} / \mathrm{min}$ step scanned from 5 to $80^{\circ}$ in $2 \theta$ angle. Scanning electron microscopy (SEM) analysis was carried out using a NOVA NANOSEM (FEI Company, USA) equipped with GAD (gaseous analytical detector), with an accelerating voltage of $5 \mathrm{kV}$.

\section{Reagents and stock solutions}

All the chemicals and reagents used in this study were of analytical grade. A $1000 \mathrm{mg} \mathrm{F} / \mathrm{L}$ fluoride stock solution was prepared by dissolving $2.21 \mathrm{~g}$ of anhydrous sodium fluoride $(99.0 \%$ $\mathrm{NaF}$, BDH Chemicals Ltd, Poole, England) and filling up to $1000 \mathrm{~mL}$ with deionized water. All the synthetic fluoride solutions for adsorption and analysis were prepared by diluting an appropriate aliquot of the stock solution in deionized water. Total ionic strength adjustment buffer (TISAB) solution was prepared by following a recommended procedure [34], except that CDTA (trans-1,2-diamineciclohexane-tetracetic acid) was replaced by EDTA.

\section{Analysis of fluoride}

A pH/ISE meter (Orion Model, EA 940 Expandable Ion Analyzer, USA) equipped with combination fluoride selective electrode (Orion Model 96-09, USA) was employed for the measurement of fluoride ion concentration. The fluoride concentration was measured according to the procedure described in the instrument's manual. The method of direct potentiometry was used, where the concentration was read directly. The fluoride ion selective electrode was calibrated prior to each experiment. All measurements were made at room temperature $(22 \pm 2$ $\left.{ }^{\circ} \mathrm{C}\right)$. 
Batch tests

All the batch experiments were conducted in $500 \mathrm{~mL}$ beaker containing $500 \mathrm{~mL}$ of fluoride spiked distilled water under continuous mixing condition with magnetic stirrer at room temperature $\left(22 \pm 2{ }^{\circ} \mathrm{C}\right)$. A sample solution was periodically taken out of the beaker and filtered through a $0.2 \mu \mathrm{m}$ filter paper for fluoride analysis. Then, residual fluoride concentration was measured immediately after equal volume of TISAB was added to $10 \mathrm{~mL}$ sample solution. All the experiments were performed in triplicate and the mean values used.

The defluoridation capacity of the material (mixture of alum, lime, and AO) at any time $\mathrm{t}\left(\mathrm{q}_{\mathrm{t}}\right.$, $\mathrm{mg} / \mathrm{g})$, and the fluoride removal efficiency (\% R) was calculated as:

$\mathrm{q}_{\mathrm{t}}=\left[\frac{\left(\mathrm{C}_{\mathrm{o}}-\mathrm{C}_{\mathrm{t}}\right)}{\mathrm{m}}\right] \times \mathrm{V}$

$\% R=\left[\frac{\left(C_{0}-C_{t}\right)}{C_{o}}\right] \times 100$

where, $C_{o}$ and $C_{t}$ are the fluoride concentrations in solution $(\mathrm{mg} / \mathrm{L})$ initially and at any time $(\mathrm{t})$, respectively, $\mathrm{m}$ the mass of the defluoridation material (alum, lime, and $\mathrm{AO}$ ) (g) and $\mathrm{V}$ is the volume (L) of the solution.

The effects of alum and $\mathrm{AO}$ dose and contact time were studied by varying the dosage of alum $(900,1200,1800$, and $2250 \mathrm{mg} / \mathrm{L})$, lime (35\% of alum dose) and AO $(195,600,1000$, 1200 and $1500 \mathrm{mg} / \mathrm{L}$ ) at constant initial fluoride concentration of $15 \mathrm{mg} / \mathrm{L}$. The effect of hybrid defluoridation material (alum, lime and AO) dose were studied at different dosage of alum (400, $800,1200$ and $16000 \mathrm{mg} / \mathrm{L}), \mathrm{AO}(45,75,105,195$ and $300 \mathrm{mg} / \mathrm{L})$, and lime (35\% of alum dose) at initial fluoride concentration of $15 \mathrm{mg} / \mathrm{L}$. The effects of initial fluoride concentration and contact time were investigated by varying fluoride concentrations from $5-30 \mathrm{mg} / \mathrm{L}$ at constant adsorbent dose of alum $(1200 \mathrm{mg} / \mathrm{L}), \mathrm{AO}(75 \mathrm{mg} / \mathrm{L})$, and lime (35\% of alum). The mixture was stirred for one hour at room temperature and a $10 \mathrm{~mL}$ portion of the sample was taken at time interval: $5,10,15,20,30$ and $60 \mathrm{~min}$. The effect of raw water $\mathrm{pH}$ on the removal of fluoride on to the defluoridation material was studied by varying the solution $\mathrm{pH}$ from $4-10$. The $\mathrm{pH}$ was adjusted to the desired level either with $0.1 \mathrm{M} \mathrm{NaOH}$ or $0.1 \mathrm{M} \mathrm{HCl}$. The $\mathrm{pH}$ was measured with $\mathrm{pH} / \mathrm{EC} / \mathrm{TDS}$ temperature meter (AD 8000, Hungary) using unfilled $\mathrm{pH}$ glass electrode. The meter was calibrated each time measurements were being performed by using $\mathrm{pH}$ calibration buffers.

Reaction kinetics was determined using fixed amount of alum/AO (1200 mg/L alum and 75 $\mathrm{mg} / \mathrm{L} \mathrm{AO})$ and $(600 \mathrm{mg} / \mathrm{L}$ alum and $37.5 \mathrm{mg} / \mathrm{L} \mathrm{AO})$ corresponding to the initial fluoride concentration of $36 \mathrm{mg} / \mathrm{L}$ and $18 \mathrm{mg} / \mathrm{L}$, respectively.

Real water samples were collected from six different sites within the Ethiopian Rift Valley. These samples were collected in clean plastic bottles and transported to laboratory for water quality analysis including fluoride to investigate the performance of the combined NT/AO process.

\section{RESULTS AND DISCUSSION}

\section{Composition and characterization of $A O$}

The major component of the solid phase of the AO was aluminum $276.9 \mathrm{mg} / \mathrm{g}$, sulfate $76 \mathrm{mg} / \mathrm{g}$ and sodium accounts $66 \mathrm{mg} / \mathrm{g}$ and other minor elements. The presence of sulfate and small amounts of iron $(13.9 \mathrm{mg} / \mathrm{g})$ in the sample would contribute to the high fluoride removal capacity of AO. Sulfate that is associated with aluminum is responsible for the acidity of the AO. The density of sun dried AO was $2.11 \mathrm{~g} / \mathrm{cm}^{3}$, that is lower than the density of thermally treated $\mathrm{AO}$ at $300{ }^{\circ} \mathrm{C}\left(2.39 \mathrm{~g} / \mathrm{cm}^{3}\right)$ [4]. 


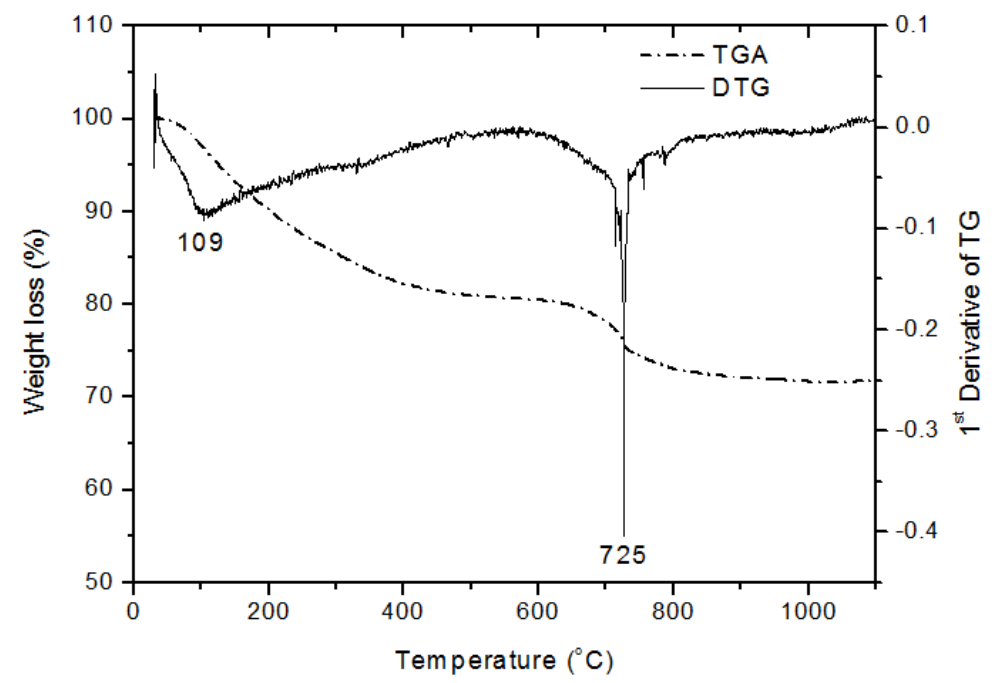

Figure 1. Thermogravimetric curve, TG (dotted line), and derivative of thermogravimetric curve DTG (solid line) of sun-dried AO.

From Figure 1, sun dried AO adsorbent showed a total weight loss of $14.87 \%$, at 100-400 ${ }^{\circ} \mathrm{C}$, which corresponds to loss of water and at $725^{\circ} \mathrm{C}$ a total weight loss of $3.96 \%$, which might be associated with the decomposition of sulfate to $\mathrm{SO}_{3}$ [35]. The material is X-ray amorphous and scanning electron microscopic (SEM) studies show AO to be a network of fibers with a size range of 200-300 $\mathrm{nm}$ (Figure 2).
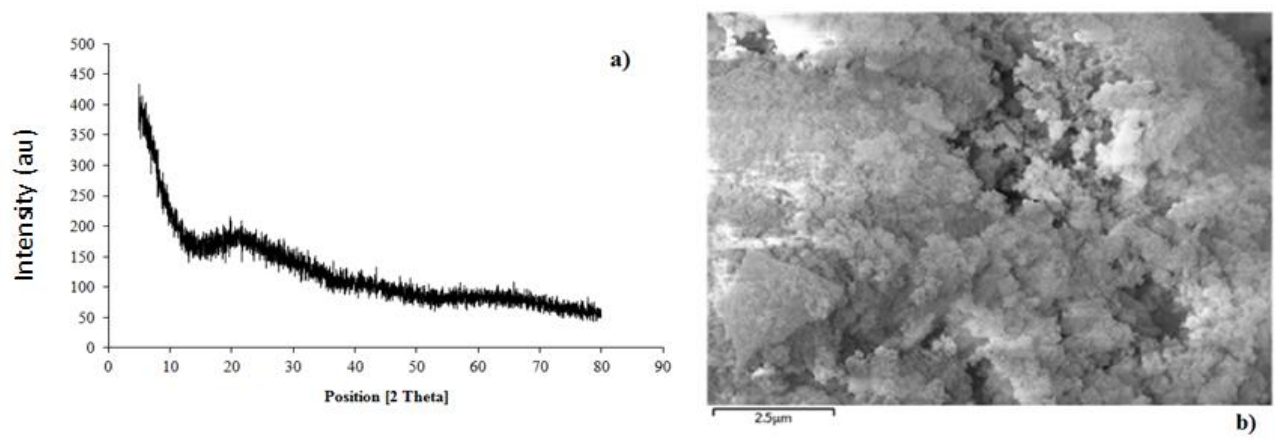

Figure 2. XRD (a) and SEM photograph (b) of AO (magnification; 10,000X), showing $\mathrm{Na}_{2} \mathrm{SO}_{4}$ and amorphous $\mathrm{Al}$ hydroxide.

\section{Batch tests}

Optimization of $A O$ and alum dose

The defluoridation efficiency was significantly increased with dose as reflected by the fluoride removal efficiency for both materials (Figure 3). The percent removal of fluoride increases, 
significantly up to adsorbent dose of $80 \mathrm{mg} \mathrm{AO} / \mathrm{mg} \mathrm{F}$. However, no significant change was observed beyond this dose under the experimental conditions used. Further increase in the dose resulted in too much sludge and meant wastage of material. The increase in fluoride adsorption efficiency was due to the large number of available fluoride binding sites resulting from the increased in adsorbent dosage. Thus, $80 \mathrm{mg} \mathrm{AO} / \mathrm{mg} \mathrm{F}$ of adsorbent dose and $60 \mathrm{~min}$ was taken as an optimum dose for this experiment for initial fluoride of $15 \mathrm{mg} / \mathrm{L}$.

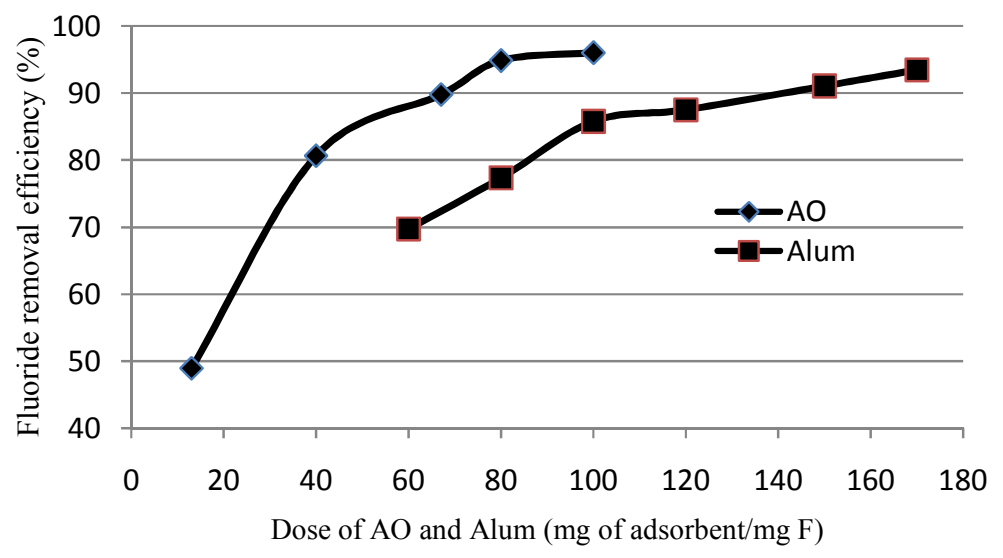

Figure 3. Fluoride removal efficiency as a function of adsorbent dose (initial fluoride concentration $=15 \mathrm{mg} / \mathrm{L}$, solution $\mathrm{pH}=6.7-7.3$, reaction time of $60 \mathrm{~min}(\mathrm{AO}), 20 \mathrm{~min}$ (alum), lime $=35 \%$ of alum).

As can be seen from Figure 3, fluoride removal performance depends on alum dose and the optimum alum dose was in the range between $150-170 \mathrm{mg}$ alum/ $\mathrm{mg} F$ which is in agreement with other previous studies [36, 37]. The actual amount of lime and alum increases with an increase in the fluoride and alkalinity levels in the raw water [38]. Thus, it reaches the threshold where the users start complaining about residual sulfate salinity in the treated water, when fluoride and alkalinity levels in the raw water are high. The large dose also results in a large sludge disposal problem.

\section{Fluoride removal by a combined alum/AO material}

Table 1. Fluoride removal efficiency (\%) for various combinations of alum and $\mathrm{AO}$ at constant initial fluoride concentration of $15 \mathrm{mg} / \mathrm{L}$ and contact time of $15 \mathrm{~min}$.

\begin{tabular}{|c|c|c|c|c|}
\hline $\begin{array}{c}\text { AO dose } \\
\text { Alum dose }\end{array}$ & $\begin{array}{c}60 \\
\text { (mg alum/mg F) }\end{array}$ & $\begin{array}{c}80 \\
\text { (mg alum/mg F) }\end{array}$ & $\begin{array}{c}100 \\
\text { (mg alum/mg F) }\end{array}$ & $\begin{array}{c}120 \\
\text { (mg alum/mg F) }\end{array}$ \\
\hline $3(\mathrm{mg} \mathrm{AO} / \mathrm{mg} \mathrm{F})$ & 87.2 & 92.9 & 93.3 & 96.3 \\
\hline $5(\mathrm{mg} \mathrm{AO} / \mathrm{mg} \mathrm{F})$ & 88.6 & 93.8 & 94.9 & 96.8 \\
\hline $7(\mathrm{mg} \mathrm{AO} / \mathrm{mg} \mathrm{F})$ & 88.9 & 94.0 & 95.2 & 97.1 \\
\hline $13(\mathrm{mg} \mathrm{AO} / \mathrm{mg} \mathrm{F})$ & 90.6 & 94.9 & 95.3 & 97.3 \\
\hline $20(\mathrm{mg} \mathrm{AO} / \mathrm{mg} \mathrm{F})$ & 93.5 & 95.3 & 96.8 & 97.6 \\
\hline
\end{tabular}

It is evident that, in all the combination of AO with NT, the fluoride removal process was fast and most of the fluoride ions were removed in the first $15 \mathrm{~min}$. It was observed from Table 1, the fluoride removal efficiency was increased from 87.2 to $97.6 \%$ at $15 \mathrm{mg} / \mathrm{L}$ initial fluoride 
concentration and 15 min contact time. The percent removal of fluoride increased significantly in each combination. However, after a dose of $80 \mathrm{mg}$ alum/mg F and $5 \mathrm{mg} \mathrm{AO} / \mathrm{mg} \mathrm{F}$, the amount removed per unit of alum/AO declined. Higher doses of the alum/AO (i.e., greater than $80 \mathrm{mg}$ alum $/ \mathrm{mg} \mathrm{F}$ and $5 \mathrm{mg} \mathrm{AO} / \mathrm{mg} \mathrm{F}$ ) could increase the amount of sludge without significant benefit in the amount of fluoride removed. This dose $(80 \mathrm{mg}$ alum $/ \mathrm{mg} \mathrm{F}$ and $5 \mathrm{mg} \mathrm{AO} / \mathrm{mg} \mathrm{F}$ ) also is sufficient to reduce the amount of fluoride in drinking water to less than $1.5 \mathrm{mg} / \mathrm{L}$, the WHO drinking water guideline. Hence, it is considered as an optimum dose for the hybrid fluoride technology.

\section{Effect of initial fluoride concentration}

The removal of fluoride at a constant alum/AO combination of $80 \mathrm{mg}$ alum/mg $\mathrm{F}$ and $5 \mathrm{mg}$ $\mathrm{AO} / \mathrm{mg} \mathrm{F}$ is shown in Figure 4 as a function of initial fluoride concentrations and contact time. As shown in Figure 4, the fluoride removal efficiency is high at lower initial fluoride concentration. The fluoride removal efficiency of about $93 \%$ was observed when the initial fluoride was less than or equal to $15 \mathrm{mg} / \mathrm{L}$ for a contact time of $15 \mathrm{~min}$. This indicates that desirable contact time is significant for fluoride removal since the removal of more concentrated solution approached equilibrium slowly. On the other hand, for a given mass of alum/AO, the removal efficiency of alum/AO was found to decrease with the increase in the initial concentration.

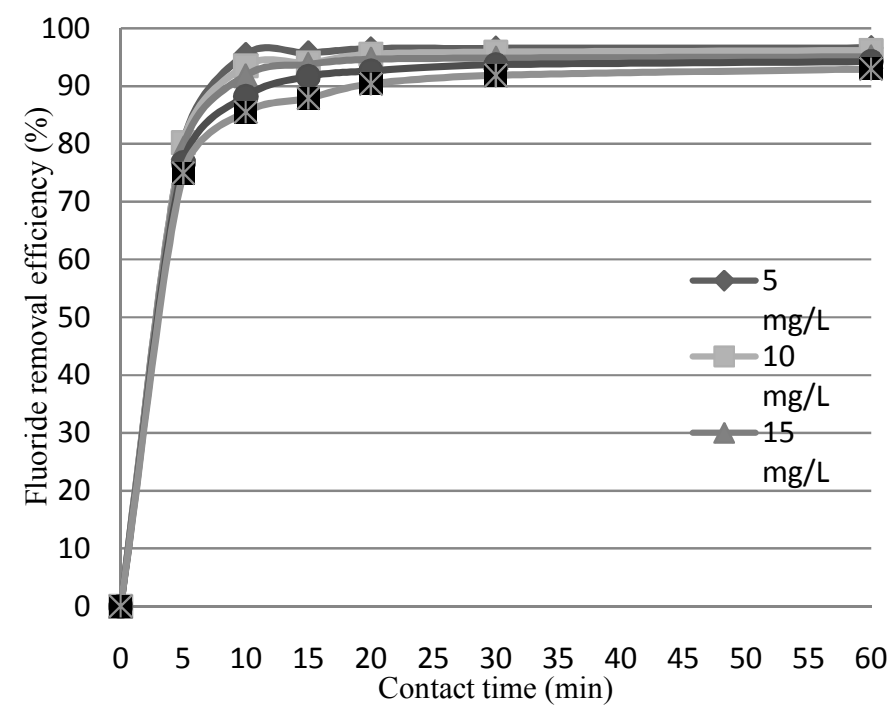

Figure 4. Fluoride removal efficiency as a function of contact time $(80 \mathrm{mg}$ alum/ $\mathrm{mg} \mathrm{F}$ and $5 \mathrm{mg}$ $\mathrm{AO} / \mathrm{mg} \mathrm{F}$, and lime $35 \%$, initial $\mathrm{pH}=7.0 \pm 0.3$ ).

\section{Effect of solution $\mathrm{pH}$}

Figure 5, shows the influence of solution $\mathrm{pH}$ on fluoride removal efficiency of alum/AO. It is apparent that percentage fluoride removals remain nearly constant within the $\mathrm{pH}$ range of 5-9, which is suitable for practical application in the Ethiopian Rift Valley region both at household and community water treatment systems. The removal efficiency decreased sharply when the 
$\mathrm{pH}$ is below 5.0, or above 9.0. For solution $\mathrm{pH}$ values greater than 9.0 , the fluoride removal by alum/AO was reduced possibly contributed by two factors: the electrostatic repulsion of fluoride ions to the negatively charged surface of the $\mathrm{Al}(\mathrm{OH})_{4}{ }^{-}$and competition from excessive amounts of hydroxide ions [39]. The main fluoride species present in acidic solutions are positively charged $\mathrm{AlF}^{2+}, \mathrm{AlF}_{2}^{+}$and $\mathrm{AlF}_{3}$ species while the surface of the precipitate is also positively charged. Therefore, the removal of fluoride was decreased in acidic solutions because of the electrostatic repulsion [40] or the combined effect of both chemical and electrostatic interactions between the flocculated surface and fluoride ion.

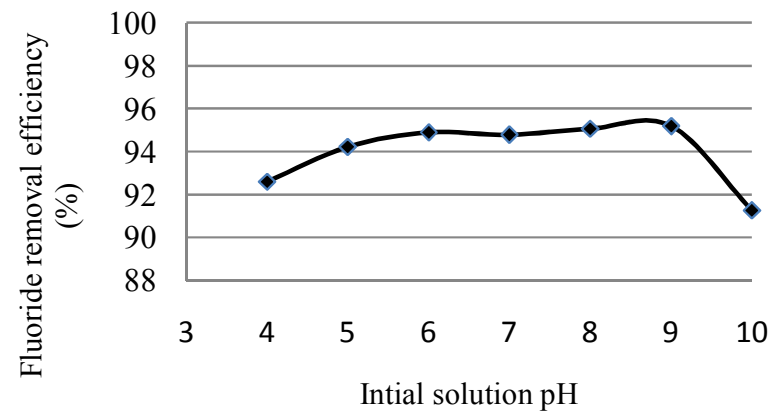

Figure 5. Effect of solution $\mathrm{pH}$ on fluoride removal efficiency $(80 \mathrm{mg}$ alum/mg $\mathrm{F}$ and $5 \mathrm{mg}$ $\mathrm{AO} / \mathrm{mg} \mathrm{F}$, lime $35 \%$, initial fluoride $=15 \mathrm{mg} / \mathrm{L}$ ).

Fluoride removal kinetics

The kinetic analysis of the adsorption data is based on reaction kinetics of pseudo-first orders and pseudo-second order mechanisms. The experimental data were well fitted to pseudo-second order rate equation by using the Lagergren's rate equation as shown below [41]:

$$
\frac{t}{q_{t}}=\frac{1}{k_{2} q_{e}{ }^{2}}+\frac{t}{q_{e}}
$$

where $q_{e}$ and $q_{t}$ are the amount of adsorbed fluoride at equilibrium and any time $\mathrm{t}(\mathrm{mg} / \mathrm{g})$, respectively. $K_{2}$ (g/mg.min) is equilibrium rate constant of second order sorption and $\mathrm{t}$ is the contact time (min). The rate constant $K_{2}$, can be determined by plotting $t / q_{t}$ vs. $\mathrm{t}$ based on equation (3).

Figure 6 shows the average pseudo-second order plot of fluoride removal kinetics on the material. Thus, the average rate constant of the combined NT/AO was found to be 2.22 $\mathrm{g} / \mathrm{min} . \mathrm{mg})\left(\mathrm{x} 10^{-3}\right)$ and the correlation coefficient was found to be near to unity. Therefore, the pseudo-second order model is suitable to describe the kinetics of a hybrid NT/AO technology. 


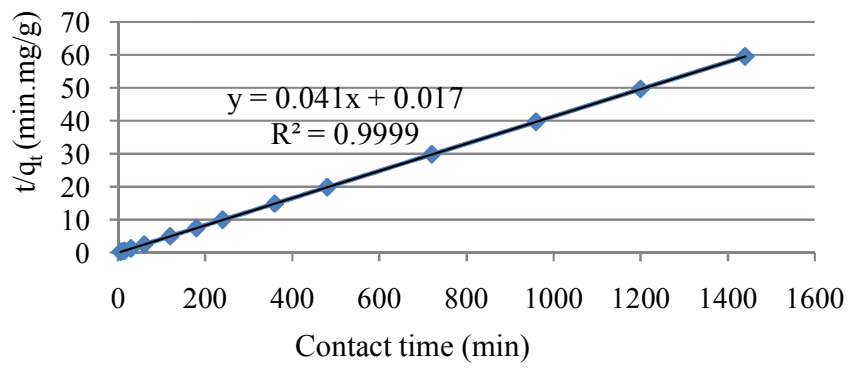

Figure 6. Average pseudo-second-order plot of fluoride removal kinetics of NT/AO $(\mathrm{pH}=7.0)$.

\section{Application of combined process for real water sample}

Experiments on the fluoride removal efficiency of the hybrid NT/AO were conducted using ground water samples taken from six selected community water supply schemes in Rift Valley Region; Oromia Region, East Showa Zone, Bora Woreda (Jitu and Gora Laman Kebele) and Dugda Woreda (Giraba Jawe, Tuchi, Dodota Denbel, Tepho Choroke Kebele).

As shown in Table 2, the initial fluoride concentrations of the community water schemes were $10.7,25.4,9.63,12.6,9.56$ and $8.87 \mathrm{mg} / \mathrm{L}$ and the treated water at dosing rate of $90 \mathrm{mg}$ alum $/ \mathrm{mg} \mathrm{F}, 5 \mathrm{mg} \mathrm{AO} / \mathrm{mg} \mathrm{F}$ and lime $15 \%$ of alum were $1.08,1.62,1.35,1.29,1.42$ and 1.47 $\mathrm{mg} / \mathrm{L}$, respectively. It was observed that the samples from rift valley require more alum dose but less lime than the simulated sample prepared in the lab to enhance the fluoride removal efficiency, which could be due to the high alkalinity of the real sample. On the other hand, the quality of the treated water with respect to aluminium and sulfate is within acceptable range of WHO guideline.

The Nalgonda Technique treatment efficiency is limited to about $70 \%$ even at higher dose of alum (150-170 mg/mg F) and thus the process would be less satisfactory in case of medium to high fluoride contaminated water. The present treatment efficiency is in the range of $85-93 \%$ at dose of $90 \mathrm{mg}$ alum/mg F, $5 \mathrm{mg} \mathrm{AO} / \mathrm{mg} \mathrm{F}$ and lime $15 \%$ of alum. In addition, the water quality parameters measured were within WHO guideline values. Evidently, the proposed process displays high efficiency in case of medium to high fluoride contaminated ground water samples with less sludge production.

Table 2. Defluoridation of real water samples from selected Woredasin Oromia Regional State using a hybrid NT/AO technology.

\begin{tabular}{|c|c|c|c|c|c|c|c|c|c|c|c|c|}
\hline \multirow{3}{*}{$\begin{array}{l}\text { Drinking water } \\
\text { quality } \\
\text { parameters }\end{array}$} & \multicolumn{8}{|c|}{ Dugda Woreda } & \multicolumn{4}{|c|}{ Bora Woreda } \\
\hline & \multicolumn{2}{|c|}{ Dodota Denbel } & \multicolumn{2}{|c|}{ Tuchi } & \multicolumn{2}{|c|}{ Tepho Choroke } & \multicolumn{2}{|c|}{ Giraba Jawe } & \multicolumn{2}{|c|}{ Jitu } & \multicolumn{2}{|c|}{ Gora Laman } \\
\hline & RW & TW & RW & TW & RW & RW & RW & TW & RW & TW & RW & TW \\
\hline Fluoride, mg/L & 10.7 & 1.08 & 9.63 & 1.35 & 12.6 & 1.62 & 25.4 & 1.29 & 9.56 & 1.42 & 8.87 & 1.47 \\
\hline $\mathrm{pH}$ & 8.74 & 6.24 & 7.87 & 6.67 & 8.45 & 8.22 & 6.51 & 6.22 & 7.95 & 6.44 & 7.87 & 6.21 \\
\hline $\mathrm{EC}(\mu \mathrm{s} / \mathrm{cm})$ & 1242 & 1479 & 1531 & 1677 & 807 & 2390 & 975 & 2800 & 1436 & 1635 & 1212 & 1432 \\
\hline TDS (mg/L) & 621 & 739 & 766 & 839 & 606 & 1195 & 716 & 1400 & 718 & 818 & 606 & 716 \\
\hline $\begin{array}{l}\text { Alkalinity } \mathrm{mg} / \mathrm{L} \\
\text { as } \mathrm{CaCO}_{3}\end{array}$ & 550 & - & 950 & - & 530 & 625 & - & - & 975 & - & 1050 & - \\
\hline $\begin{array}{c}\text { Aluminium, } \\
\mathrm{mg} / \mathrm{L}\end{array}$ & 0.01 & 0.17 & 0.01 & 0.19 & 0.01 & 0.01 & 0.10 & 0.21 & 0.01 & 0.08 & \begin{tabular}{|l|}
0.01 \\
\end{tabular} & 0.09 \\
\hline Sulfate, $\mathrm{mg} / \mathrm{L}$ & 67 & 175 & 30 & 160 & 50 & 15 & 150 & 170 & 62 & 164 & 71 & 165 \\
\hline
\end{tabular}

$\mathrm{RW}=$ raw water, $\mathrm{TW}=$ treated water.

Bull. Chem. Soc. Ethiop. 2016, 30(3) 
Application for household scale defluoridation

The application of the alum/AO technology at household scale was demonstrated by using a plastic container of 10 liter capacity filled with fluoride contaminated real water sample (10 $\mathrm{mg} / \mathrm{L}$ ). The treatment involved a 5 min stirring of the water with a wooden rod after a dose of 90 $\mathrm{mg}$ alum/mg F, $5 \mathrm{mg} \mathrm{AO} / \mathrm{mg} \mathrm{F}$ and lime $15 \%$ amount of alum. The mixture was allowed to settle for 1 hour and the clear water was decanted slowly, without disturbing the sediment, and filtered. This process produced treated water had a residual fluoride concentration below 1.5 $\mathrm{mg} / \mathrm{L}$ and $\mathrm{pH}$ range of 6.2-7.0. The treatment system does not require capital investment other than the purchase of a plastic mixing bucket and a few chemicals. This indicated that the present work could be efficiently applicable at household level in rural settings for fluoride removal from drinking water.

\section{CONCLUSIONS}

The removal of fluoride from water by a combined alum/AO technology has been demonstrated. For a given initial fluoride concentration the removal efficiency increased with increasing dose of adsorbent. Removal of fluoride was rapid in the first $15 \mathrm{~min}$ followed by a gradual increase to equilibrium. The media removes about $93 \%$ of fluoride from water at dose of $80 \mathrm{mg}$ alum $/ \mathrm{mg} \mathrm{F}$ and $5 \mathrm{mg} \mathrm{AO} / \mathrm{mg} \mathrm{F}$ and lime $35 \%$ of alum at initial fluoride concentration of $15 \mathrm{mg} / \mathrm{L}$ within the first $15 \mathrm{~min}$. The optimum solution $\mathrm{pH}$ for fluoride removal was in the range of 5-9. The kinetic studies showed that the removal of fluoride by alum/AO can be well described by a pseudosecond-order rate equation. The samples from the Rift Valley required more dose of alum and less lime than the simulated sample prepared in a laboratory setting, because of high alkalinity of the real water samples. The alum/AO process would be efficient in case of medium to high fluoride contaminated real water and produced less sludge as compared with Nalgonda Technology alone. It is evident that, the combined alum/AO based fluoride removal technology can be employed for removing the fluoride from water at household scale.

\section{ACKNOWLEDGEMENTS}

This research was supported by the National Science Foundation (NSF) and USAID PEER (grant number AID-OAA-A-11-00012) to Feleke Zewge. We thank EAWAG (Swiss Federal Institute of Aquatic Science and Technology) for doing the TGA, XRD, and SEM analyses.

\section{REFERENCES}

1. Saxena, V.K.; Ahmed, S. Environ. Geol. 2003, 43, 731.

2. Edmunds, M.; Smedley, P. Fluoride in Natural Waters in Essentials of Medical Geology, Selinus, O.; Alloway, B.; Centano, J.; Finkelman, R.; Fuge, R.; Lindh, U.; Smedley, P. (Eds.), Elsevier Academic Press: Burlington; 2005; p 301.

3. Handa, B.K. Ground Water 1975, 13, 275.

4. Mulugeta, E.; Zewge, F.; Johnson, C.A.; Chandravanshi, B.S. Desalin. Water Treat. 2014, 52,5422 .

5. World Health Organization Guidelines for Drinking Water Quality, 4th ed., World Health Organization: Geneva, Switzerland; 2011.

6. Tekle-Haimanot, R.; Fekadu, A.; Bushura, B.J. Trop. Geogr. Med.1987, 39, 209.

7. Zeng, B.; Hong, Y. Geochemical Environment Related to Human Endemic Fluorosis in China in Geochemistry and Health, Science Reviews: London; 1988.

8. Dissanayake, C.B. Int. J. Environ. Stud. 1991, 38, 137. 
Combined aluminium sulfate/hydroxide process for fluoride removal from drinking water 401

9. Reimann, C.; Banks, D. Sci. Total Environ. 2004, 532, 13.

10. Zewge, F. Solution to the fluoride problem in the rift valley region of Ethiopia, A Biannual News Lett. Chem. Soc. Ethiop.; 2005; p 15.

11. Tekele-Haimanot, R.; Melkamu, Z.; Kloos, H.; Riemann, C.; Fantaye, W.; Zerihun, L.; Bjoruatn, K. Sci. Total Environ. 2006, 367, 182.

12. Kloos, H.; Tekle-Haimanot, R. Trop. Med. Inter. Health 1999, 4, 355.

13. Tekle-Haimanot, R. Study of fluoride and fluorosis in Ethiopia with recommendations on appropriate defluoridation technologies, Consultancy Report, UNICEF-Ethiopia; 2005; $\mathrm{p} 1$.

14. Reardon, E.J.; Wang, Y.X. Environ. Sci. Technol. 2000, 34, 3247.

15. Wang, H.; Ji, J.; Liu, L. Acta Petrol. Mineral. 2003, 22, 71.

16. Zevenbergen, C.; van Reeuwijk, L.P.; Frapporti, G.; Louws, R.J.; Schuiling, R.D. Sci. Total Environ. 1996, 188, 225.

17. Lu, H.; Wang, B.; Ban, Q. Energy Sources, Part A 2010, 32, 1509.

18. Srimurali, M.; Pragathi, A.; Karthikeyan, J. Environ. Pollut. 1998, 99, 285.

19. Nagappa, B.; Chandrappa, G.T. Microporous Mesoporous Mater. 2007, 106, 212.

20. Moges, G.; Zewge, F.; Socher, M. J. Afr. Earth Sci. 1996, 21, 479.

21. Nigussie, W.; Zewge, F.; Chandravanshi, B.S. J. Hazard. Mater. 2007, 147, 954.

22. Shimelis, B.; Zewge, F.; Chandravanshi, B.S. Bull. Chem. Soc. Ethiop. 2006, 20, 17.

23. Alemu, S.; Mulugeta, E.; Zewge, F.; Chandravanshi, B.S. Environ. Technol. 2014, 15, 1893.

24. Adeno, F.; Mulugeta, E.; Zewge, F.; Chebude, Y. Bull. Chem. Soc. Ethiop. 2014, $28,215$.

25. Gómez-Hortigüela, L.; Pérez-Pariente, J.; García, R.; Chebude, Y.; Díaz, I. Sep. Purif. Technol. 2013, 120, 224.

26. Ayoob, S.; Gupta, A.K.; Bhat, V.T. Critical Rev. Environ. Sci. Technol. 2008, 38, 401.

27. Nawlakhe, W.G.; Rao, A.V.J. J. Indian Water Works Assoc. 1990, 13, 287.

28. Nawlakhe, W.G.; Kulkarni, D.N.; Pathak, B.N.; Bulusu, K.R. Indian J. Environ. Health 1975, 17, 26 .

29. Bulusu, K.R.; Sunderasan, B.B.; Pathak, B.N.; Nawlakhe, W.G.; Kulkarni, D.N.; Thergaonkar, V.P.J. J. Inst. Eng. Ind. 1979, 60, 1.

30. Feleke, Z.; Bekele, A. Alem Tena Catholic Church Defluoridation Pilot Study, Final Report, Ethiopia; 2000; 1.

31. Jagtap, S.; Yenkie, M.K.; Labhsetwar, N.; Rayalu, S. Chem. Rev. 2012, 112, 2454.

32. Meenakshi, Maheshwari, R.C. J. Hazard. Mater. 2006, 137, 456.

33. Goldberg, S.; Davis, J.A.; Hem, J.D. The surface chemistry of aluminium oxides and hydroxides in The Environmental Chemistry of Aluminium, Sposito, G. (Ed.), 2nd ed., Lewis Publishers: Boca Raton; 1996; p 33.

34. Bailey, P.L. Analysis with Ion-selective Electrodes, 3rd ed., Heidon: London; 1980; p 196.

35. Kim, J.J.; Kim, S.J. Korean J. Environ. Sci. Technol. 2003, 37, 2120.

36. Dahi, E. Sorption Isotherm of Fluoride on Flocculated Alumina, The International Society for Fluoride Research, The $1^{\text {st }}$ International Workshop on Fluorosis Prevention and Defluoridation of Water, Ngurdoto, Tanzania; 1995.

37. MoWE, Fluoride Distribution in the Ethiopian Rift and Adjacent Highlands, Final Report. Ministry of Water and Energy, National Fluorosis Mitigation Project Office, Addis Ababa; 2011.

38. Shrivastava, B.K.; Vani, A. Asian J. Exp. Sci. 2009, 23, 269.

39. Raichur, A.M.; Basu, M.J. Sep. Purif. Technol. 2001, 24, 121.

40. Sujana, M.G.; Thakur, R.S.; Rao, S.B. Colloid Interf. Sci. 1998, 275, 355.

41. Sarkar, M.; Banerjee, A.; Pramanick, P.P.; Sarkar, A.R. J. Colloid Interf. Sci. 2006, 302, 432. 